\title{
The effect of statins on psoriasis severity: a meta-analysis of randomized clinical trials
}

Mateusz Socha ${ }^{1}$, Aldona Pietrzak², Ewelina Grywalska³, Daniel Pietrzak ${ }^{4}$, Dariusz Matosiuk ${ }^{5}$ Paweł Kiciński ${ }^{6}$, Jacek Rolinski ${ }^{3}$

\author{
${ }^{1}$ Department of Internal Medicine and Cardiology, $1^{\text {st }}$ Military Clinical Hospital, Lublin, \\ Poland \\ ${ }^{2}$ Department of Dermatology, Venereology and Pediatric Dermatology, \\ Medical University of Lublin, Lublin, Poland \\ ${ }^{3}$ Department of Clinical Immunology and Immunotherapy, Medical University \\ of Lublin, Lublin, Poland \\ ${ }^{4}$ Department of Anaesthesiology and Intensive Care, Medical University of Lublin, \\ Lublin, Poland \\ ${ }^{5}$ Department of Synthesis and Chemical Technology of Pharmaceutical Substances, \\ Medical University of Lublin, Lublin, Poland \\ ${ }^{6}$ Department of Experimental Hematooncology, Medical University of Lublin, Lublin, \\ Poland
}

Submitted: 28 August 2019

Accepted: 18 October 2019

Arch Med Sci 2020; 16 (1): 1-7

DOI: https://doi.org/10.5114/aoms.2019.90343

Copyright (c 2019 Termedia \& Banach

\begin{abstract}
Introduction: Statins may reduce the severity of psoriasis, but the available evidence is unclear. We conducted a meta-analysis of randomized controlled studies (RCTs) that investigated the effect of statins on psoriasis severity assessed with the Psoriasis Area and Severity Index (PASI).

Material and methods: Two investigators searched independently the following databases: Medline, EMBASE, Cochrane Central Register of Controlled Trials and ClinicalTrials.gov from inception to February 2019. Additionally, reference lists from all available articles were searched manually. We included only RCTs carried out among adult ( $\geq 16$ years) patients with psoriasis who received oral statins for $\geq 8$ weeks and had psoriasis severity assessed with the PASI at baseline and at the end of follow-up. We used random effects meta-analysis to calculate the mean difference (D) in PASI change between patients who received either a statin or a comparator. Results: Of 279 records identified, there were 5 eligible RCTs, with a total of 223 patients, including 128 patients who received a statin (atorvastatin or simvastatin). The improvement in psoriasis severity (PASI) was significantly greater in patients who received statins than in those who received comparators $(D=2.76,95 \% \mathrm{Cl}: 0.49-5.04, p=0.017)$. In subgroup analyses, the improvement in PASI values was significant for simvastatin $(D=3.70$, $95 \% \mathrm{Cl}: 2.52-4.89, p<0.001)$ but not for atorvastatin $(D=2.30,95 \% \mathrm{Cl}$ : $-1.28-5.88, p=0.210)$.

Conclusions: Oral statins may improve psoriasis, particularly in patients with severe disease. This observation should be verified in long-term, well-designed studies that will enable analyses adjusted for clinical variables.
\end{abstract}

Key words: hydroxymethylglutaryl-CoA reductase inhibitors, psoriasis, simvastatin, atorvastatin.

\author{
Corresponding author: \\ Aldona Pietrzak MD, PhD \\ Department of Dermatology \\ and Paediatric Dermatology \\ Medical University of Lublin \\ 13 Stanisława Staszica St \\ 20-081 Lublin, Poland \\ Phone: +48 815323647 \\ E-mail: \\ aldonkapietrzak@o2.pl
}




\section{Introduction}

Psoriasis is a systemic inflammatory disease that affects from $0.51 \%$ to $11.43 \%$ of the population [1]. Depending on the extent and severity of psoriasis, patients receive either topical treatment (e.g. tars, urea ointments, vitamin D, corticosteroids) or systemic therapies (phototherapy, immunosuppressants, biologicals) [2]. Psoriasis not only affects the skin and joints, but it is also a systemic disease that frequently coexists with other conditions, primarily with metabolic syndrome [1, 3].

Statins are the mainstay of treatment for hyperlipidemia, and they work by inhibiting 3-hydroxy-3-methylglutaryl coenzyme-A reductase, a key enzyme involved in the synthesis of cholesterol $[4,5]$. However, statins also have immunomodulatory effects, which could be beneficial in psoriasis. For example, statins reduce arterial wall inflammation [6]. Moreover, in the skin, statins favor Th1-mediated immune responses, inhibit the induction of MHC II, prevent cytokine release from mast cells and mast cell degranulation, and inhibit interactions between pro-inflammatory chemokines $[7,8]$.

There is evidence that statins reduce the cardiovascular risk in patients with psoriasis. However, the results of studies on the effect of statins on the clinical course of psoriasis are not consistent. Although many investigators have reported that statins reduce the risk of psoriasis progression [7, 9-16], some evidence suggests that statins may worsen psoriatic skin lesions [17-22].

We aimed to analyze the existing evidence from well-designed studies on the effect of statins

\begin{tabular}{|c|c|}
\hline $\begin{array}{c}\text { Cochrane databases: } 34 \\
\text { EMBASE: } 170 \\
\text { PubMed: } 74 \\
\text { Clinicaltrials.gov: } 1\end{array}$ & \multirow{8}{*}{$\begin{array}{c}\text { Excluded: } 193 \\
\text { No statins used: } 36 \\
\text { Change in PASI not } \\
\text { studied: } 35 \\
\text { Case report: } 33 \\
\text { Review article: } 31 \\
\text { No clinical trial: } 25 \\
\text { No psoriasis study: } 7 \\
\text { Conference paper: } 7 \\
\text { In vitro study: } 5\end{array}$} \\
\hline$\downarrow$ & \\
\hline Citations retrieved: 279 & \\
\hline$\downarrow$ & \\
\hline $\begin{array}{l}\text { Title and abstract } \\
\text { retrieved: } 198\end{array}$ & \\
\hline$\downarrow$ & \\
\hline $\begin{array}{l}\text { Articles eligible } \\
\text { for extraction: } 5\end{array}$ & \\
\hline & \\
\hline
\end{tabular}

Duplicate citations: 81

Figure 1. Flowchart showing selection of studies for meta-analysis on psoriasis severity. Thus, we conducted a metaanalysis of randomized controlled trials (RCTs) that assessed the change in the Psoriasis Area and Severity Index (PASI), a measure of psoriasis severity, after treatment with either statins or comparators.

\section{Material and methods}

This meta-analysis was conducted in accordance with the Preferred Reporting Items for Systematic Reviews and Meta-Analyses (PRISMA) statement [23].

\section{Search strategy}

Two investigators (A.P. and D.P.) searched independently the following databases: PubMed, EMBASE, Cochrane Central Register of Controlled Trials, and ClinicalTrials.gov. The databases were searched using a highly sensitive search strategy to identify RCTs [24] - we used the following search terms in titles and abstracts: (statin OR statins OR simvastatin OR atorvastatin OR pravastatin OR rosuvastatin OR fluvastatin OR hydroxymethylglutaryl-CoA reductase inhibitors) AND (psoriasis OR psoriatic arthritis). The search was not restricted to any particular language, and included the period from inception to February 2019. Reference lists from all available review articles and RCTs were also searched manually.

\section{Study selection}

Original studies were included in the meta-analysis if they met the following criteria: (1) being an RCT, (2) carried out among adults ( $\geq 16$ years), (3) recruiting psoriatic patients who received oral statins for $\geq 8$ weeks, and (4) psoriasis severity assessed with the PASI at baseline and at the end of follow-up. Exclusion criteria were: (1) non-clinical study, (2) carried out among patients under 16 years old, (3) not using statins, and (4) not assessing psoriasis severity by PASI. To avoid double counting of patients included in more than one article by the same authors or research groups, patient recruitment periods were evaluated. Titles and abstracts of retrieved articles were independently evaluated by two investigators (D.P. and E.G.). Full-text articles were reviewed when abstracts did not provide sufficient information about inclusion and exclusion criteria. The full text of each article was reviewed independently, and its eligibility for inclusion in the meta-analysis was evaluated. Results were compared and discrepancies resolved through discussion and, if necessary, by judgment of another investigator (D.M.). Figure 1 presents the selection of studies for the meta-analysis. 


\section{Risk of bias assessment}

The risk of bias in each eligible study was assessed independently by two investigators (M.S and J.R.) with the Cochrane Collaboration's risk of bias tool. The risk of bias was assessed separately for random sequence generation, allocation concealment, blinding of participants and personnel, blinding of outcome assessment, analysis of incomplete outcome data, selective reporting, and in other areas. All these judgments were categorized as 'yes' (low risk of bias), 'unclear', or 'no' (high risk of bias) [25].

\section{Primary outcomes}

The primary outcome of interest was a continuous variable: the mean reduction in the PASI from baseline to the end of follow-up in patients who received either statins or comparators.

\section{Data extraction}

Extracted data included information about the study design, characteristics, and number of participants, drug and dose, permitted concomitant therapies, follow-up period, change in skin disease outcomes, adverse effects, and withdrawals. The details were summarized in standard extraction sheets, independently by two investigators (A.P. and M.S.). Another investigator (P.K.) reviewed the extraction sheets. For studies that presented data on figures only, values of interest were obtained with Plot Digitizer software, Version 2.5.1 (http:// plotdigitizer.sourceforge.net/).

\section{Statistical analysis}

A random effects meta-analysis was conducted with Statistica 10 software (StatSoft, Tulsa, OK, USA). The outcomes were calculated as mean differences (D, with 95\% confidence intervals $(95 \% \mathrm{Cls})$ ) between patients who received either statins or comparators. Homogeneity of the studies was verified with the T2 test by the weighted least square method. A post hoc sensitivity analysis was conducted to examine whether the overall findings were robust to any outlying studies. In the sensitivity analysis, sequential meta-analyses were repeated in which each study was excluded. Subgroup analyses were also carried out to determine the individual effects of atorvastatin and simvastatin. The results of all tests were considered significant at $p<0.05$.

\section{Results}

Of 279 records initially identified, the titles and abstracts of 198 studies were assessed for eligibility after exclusion of duplicates (Figure 1). A total of 193 records were excluded because they did not analyze statin use $(n=36)$, did not use PASI $(n=35)$, did not concern psoriasis $(n=7)$, or were case reports $(n=33)$, reviews $(n=31)$, not clinical trials $(n=25)$, conference papers $(n=7)$, in vitro studies $(n=5)$, letters $(n=4)$, withdrawn studies $(n=2)$, animal studies $(n=2)$, erratum $(n=1)$, ongoing study $(n=1)$, not randomized $(n=1)$, had too short an intervention period $(n=1)$, no access $(n=1)$, or had no data available $(n=1)$.

Of the five RCTs, only Faghihi et al. [14] provided detailed information about the randomization method, and none of the RCTs specified whether allocation concealment was performed. In the study conducted by Naseri et al. [11], assessors were blinded to treatment allocation. The study conducted by Vasiuk et al. [12] was an open-label trial, and Faghihi et al. [14] did not provide information about the blinding of outcome assessment. Withdrawals were reported by Faghihi et al. [14], and only two patients from that study (one from the statin arm and one from the placebo arm) did not complete the trial, which was unlikely to have influenced the outcomes. In contrast, 16 patients (8 patients in the statin arm) withdrew from the study by Chua et al. [26], which could have influenced the outcome (Table I).

Of the five RCTs, 128 patients received statins, and 75 patients received placebo or other comparators. Meta-analysis of the included studies showed that the use of statins was associated with a greater decrease in PASI values than the use of placebo or comparators ( $D=3.57$, $95 \% \mathrm{Cl}: 2.44-4.69, p<0.001$, Figure 2). In subgroup analyses, the mean PASI reduction was significant for simvastatin $(D=3.70,95 \% \mathrm{Cl}$ : $2.52-4.89$, $p<0.001)$ but not for atorvastatin $(D=2.30$, $95 \% \mathrm{Cl}:-1.28-5.88, p=0.21$; Figure 2 ).

Visual inspection of the forest plot and statistical tests demonstrated considerable heterogeneity among studies. Sensitivity analysis (each study sequentially excluded) revealed that the result of the meta-analysis was dependent on the outcomes of the studies conducted by Naseri et al. [11], Trong et al. [27], and Vasiuk et al. [12]. After exclusion of either study, the effect of statin therapy on PASI values was no longer significant (Table II).

\section{Discussion}

The lipid-lowering effects of statins are well described. However, the pleiotropic effects on comorbidities are still being investigated. The results of selected meta-analyses indicate no significant effect of statin therapy on pulmonary arterial hypertension and blood pressure in normotensive and hypertensive subjects $[28,29]$. However, the use of statins should be indicated in cardiovascular prevention in special groups of patients such as non-dialysis-dependent chronic kidney disease or HIV-infected 
Table I. Characteristics of randomized controlled trials included in the meta-analysis

\begin{tabular}{|c|c|c|c|c|c|}
\hline Study & $\begin{array}{l}\text { Population } \\
\text { (country) }\end{array}$ & Intervention & Comparator & $\begin{array}{l}\text { Outcome: PASI } \\
\text { (mean change } \\
\pm \text { SD) } \\
\text { Follow-up }\end{array}$ & Withdrawals \\
\hline $\begin{array}{l}\text { Chua et al. [26] } \\
\text { Randomized, } \\
\text { double-blinded, } \\
\text { placebo- } \\
\text { controlled }\end{array}$ & $\begin{array}{c}\text { Patients } \\
\text { with mild- } \\
\text { to moderate } \\
\text { psoriasis, } \\
\text { PASI < } 10 \text { (India) }\end{array}$ & $\begin{array}{c}\text { Atorvastatin } \\
40 \text { mg once daily } \\
(n=14)\end{array}$ & $\begin{array}{c}\text { Placebo }(n=14), \\
\text { topical steroids } \\
\text { allowed in both } \\
\text { arms }\end{array}$ & $\begin{array}{l}2.15 \pm 2.17 \text { vs. } \\
1.69 \pm 2.36 \\
6 \text { months of } \\
\text { follow-up }\end{array}$ & $\begin{array}{l}\text { Statin arm } \\
(n=8) \\
\text { Placebo arm } \\
(n=6)\end{array}$ \\
\hline $\begin{array}{l}\text { Naseri et al. [11] } \\
\text { Randomized } \\
\text { double-blinded } \\
\text { placebo-controlled }\end{array}$ & $\begin{array}{l}\text { Patients with } \\
\text { psoriasis (Iran) }\end{array}$ & $\begin{array}{c}\text { Simvastatin } \\
40 \text { mg once daily } \\
(n=15)\end{array}$ & Placebo $(n=15)$ & $\begin{array}{c}5.68 \pm 2.71 \text { vs. } \\
1.66 \pm 0.74 \\
8 \text { weeks of } \\
\text { follow-up }\end{array}$ & None \\
\hline $\begin{array}{l}\text { Vasiuk et al. [12] } \\
\text { Randomized } \\
\text { open-label } \\
\text { non-placebo- } \\
\text { controlled }\end{array}$ & $\begin{array}{l}\text { Men with } \\
\text { psoriasis } \\
\text { and arterial } \\
\text { hypertension } \\
\text { (Russia) }\end{array}$ & $\begin{array}{l}\text { Atorvastatin } \\
20 \text { mg once daily } \\
\text { + "standard } \\
\text { therapy" }(n=48)\end{array}$ & $\begin{array}{l}\text { "Standard } \\
\text { therapy" }(n=15)\end{array}$ & $\begin{array}{l}12 \pm 5.73 \text { vs. } \\
5.5 \pm 2.45 \\
12 \text { weeks of } \\
\text { follow-up }\end{array}$ & None \\
\hline $\begin{array}{l}\text { Faghihi et al. [14] } \\
\text { Randomized } \\
\text { double-blinded } \\
\text { placebo- } \\
\text { controlled }\end{array}$ & $\begin{array}{l}\text { Patients with } \\
\text { plaque psoriasis, } \\
\text { BSA > } 10 \% \text { (Iran) }\end{array}$ & $\begin{array}{c}\text { Atorvastatin } \\
40 \text { mg once daily } \\
(n=21)\end{array}$ & Placebo $(n=21)$ & $\begin{array}{l}4.48 \pm 2.14 \text { vs. } \\
4.33 \pm 1.93 \\
12 \text { weeks of } \\
\text { follow-up }\end{array}$ & $\begin{array}{l}\text { Statin arm } \\
(n=1) \\
\text { Placebo arm } \\
(n=1)\end{array}$ \\
\hline $\begin{array}{l}\text { Trong et al. [27] } \\
\text { Randomized } \\
\text { open-label } \\
\text { non-placebo- } \\
\text { controlled }\end{array}$ & $\begin{array}{l}\text { Patients with } \\
\text { psoriasis } \\
\text { (Vietnam) }\end{array}$ & $\begin{array}{l}\text { Simvastatin plus } \\
\text { calcipotriol/ } \\
\text { steroid ointment } \\
\quad(n=30)\end{array}$ & $\begin{array}{c}\text { Only topical } \\
\text { therapy }(n=30)\end{array}$ & $\begin{array}{c}8.63 \pm 4.78 \text { vs. } \\
5.34 \pm 3.59 \\
8 \text { weeks of } \\
\text { follow-up }\end{array}$ & No data \\
\hline
\end{tabular}

BSA - body surface area affected by psoriatic lesions, PASI - Psoriasis Area and Severity Index, SD - standard deviation.

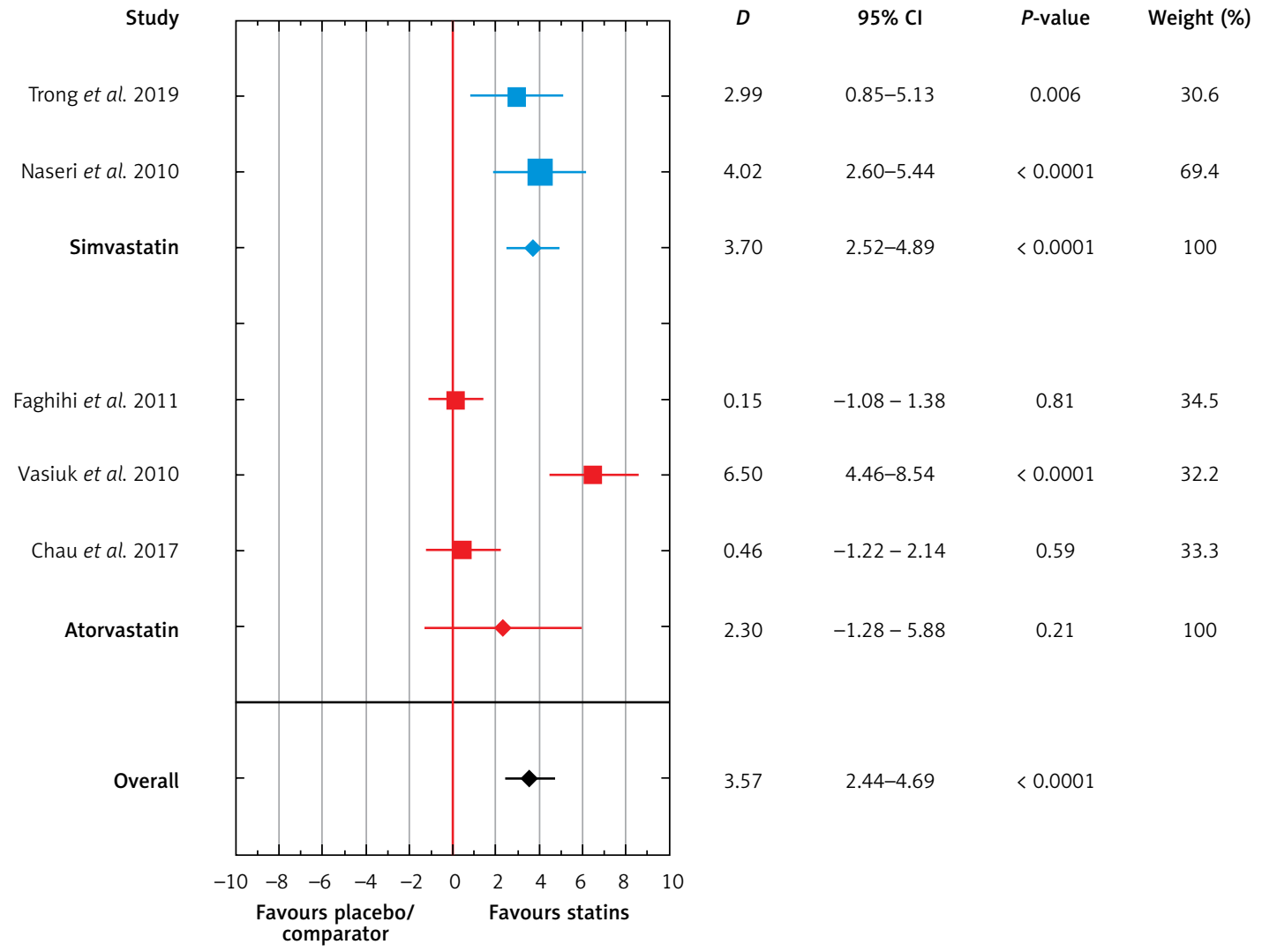

Figure 2. Meta-analysis of five RCTs of patients with psoriasis comparing mean change of PASI score after treatment with simvastatin or atorvastatin and placebo/comparator. Forest plot. Measure of the effect - the difference of means (D). Model with variable effect 
Table II. Post-hoc sensitivity analysis for randomized controlled trials (each study excluded)

\begin{tabular}{|c|c|c|c|c|c|c|}
\hline Excluded study & $D$ & $S E$ & $95 \% \mathrm{Cl}$ & $P$-value & Weight (\%) & SE (\%) \\
\hline Chau et al. [26] & 3.35 & 1.39 & $0.62 ; 6.08$ & 0.016 & 79.89 & 19.75 \\
\hline Naseri et al. [11] & 2.45 & 1.41 & $-0.3 ; 5.211$ & 0.082 & 79.24 & 21.16 \\
\hline Faghihi et al. [12] & 3.46 & 1.22 & $1.0 ; 5.867$ & 0.005 & 78.82 & 5,07 \\
\hline Vasiuk et al. [14] & 1.87 & 1.03 & $-0.1 ; 3.895$ & 0.065 & 80.88 & -11.48 \\
\hline Trong et al. [27] & 2.72 & 1.41 & $-0.04 ; 5.49$ & 0.054 & 81.17 & 21.31 \\
\hline All studies & 2.76 & 1.16 & $0.49 ; 5.04$ & 0.017 & 100 & 0 \\
\hline
\end{tabular}

$D$ - mean difference in PASI values between patients who received statins or comparators, SE - standard error, $\mathrm{Cl}-$ confidence interval.

patients [30, 31]. This meta-analysis showed that oral statins may decrease the severity of psoriatic lesions after just eight weeks. Both of the studies with simvastatin reported a reduction in the severity of psoriasis [11, 27], but two studies that compared atorvastatin with placebo did not show any effect $[14,26]$. In one study, the addition of atorvastatin to standard therapy improved the severity of psoriasis [12]. In subgroup analyses, a significant decrease in PASI values was observed for simvastatin only.

In our meta-analysis, head-to-head comparisons between individual studies were not feasible because of substantial differences in the methods used. Moreover, patients from different studies included in the meta-analysis had different baseline severities of psoriasis. In the study by Faghihi et al. [14], the mean baseline PASI value was low (about 7), and thus it was difficult to observe a significant treatment effect in that study. In contrast, in the study by Vasiuk et al., baseline PASI values were much higher (about 23), which could explain the substantial effect of atorvastatin on psoriasis severity [12]. In the study by Naseri et al. [11], patients from the statin and placebo arms differed substantially in their baseline PASI values (9.51 vs. 5.64, respectively), which may explain the greater improvement in the statin arm. Patients who received either statins or comparators had a similar psoriasis severity in the studies by Trong et al. (about 12) and Chua et al. (about 6) [26, 27].

Concomitant therapies used during the included RCTs could have had an effect on treatment outcomes. Vasiuk et al. [12], Chua et al. [26], and Trong et al. [27] did not specify whether their patients received any concomitant treatments, and participants in the studies by Faghihi et al. and Naseri et al. were allowed to use topical steroids $[11,14]$. Moreover, in the study by Faghihi et al. [14], patients were allowed to use emollients, which could have had an effect on psoriasis severity. Thus, future studies should take into account the possible effects of concomitant treatments on psoriasis outcomes.

Ramessur and Gill emphasized that the effect of statins on psoriasis severity might be different in patients with different psoriasis types [2]. Importantly, the type of psoriasis was not specified in three studies included in our meta-analysis. Moreover, none of the included studies reported the duration of psoriasis or history of previous anti-psoriatic treatments. Vasiuk et al. studied men only, including patients with different components of metabolic syndrome, arterial hypertension, and hypercholesterolemia [12]. Importantly, male sex tends to be associated with greater severity of psoriasis [2], and the effects of statins might be sex-specific [32-36].

Based on our meta-analysis, we cannot conclude whether simvastatin was superior to atorvastatin in improving psoriatic lesions because of the low number of studies and different follow-up periods. Although our meta-analysis included PASI scores documented at 12 weeks, Vasiuk et al. observed a statistically significant effect of atorvastatin on psoriasis severity at 6 months [12]. The study by Faghihi et al. was shorter, and these investigators did not observe significant differences between atorvastatin and placebo [14].

Rosuvastatin has potent lipid-lowering and anti-inflammatory effects [34, 37]. However, we did not find any RCTs that assessed the effect of rosuvastatin on psoriasis severity. In the RORA-AS study (ROsuvastatin in Rheumatoid Arthritis, Ankylosing Spondylitis and other inflammatory joint diseases), rosuvastatin was shown to improve atherosclerosis, including regression of atherosclerotic plaques, reduction of carotid wall stiffness, and improved endothelial function [35-37]. However, that study was not controlled, the patients with psoriasis were not analyzed as a separate group, and the effect on PASI was not investigated. Thus, the RORA-AS study was not included in our meta-analysis.

The findings of our meta-analysis provide evidence of beneficial effects of statin use on psoriasis patients, not only on the lipid panel, but also on psoriasis severity. Statins are a commonly prescribed drug in clinical practice and are usually well tolerated. However, adverse effects may occur, the most common being muscle syndromes, observed in 10-15\% of patients [38]. 
Our meta-analysis has some limitations. There were only a few eligible RCTs, with relatively small numbers of patients and a high risk of bias. Only one study described the randomization process in detail. The included studies were heterogeneous, with different statin usage and different psoriasis severity at the baseline.

In conclusion, the results of this meta-analysis indicate that statins, in particular simvastatin, reduce psoriasis severity, especially in patients with severe disease. Although the results of our meta-analysis show promise in the treatment of psoriasis, they need to be verified in long-term, well-designed studies that will enable analyses adjusted for clinical variables.

\section{Acknowledgments}

This work was supported by Research Grant No. DS. 460 of the Medical University of Lublin and DS. 168. The authors would like to thank Proper Medical Writing Sp. z o.o. for language correction by a native English speaker of the final version of our manuscript.

\section{Conflict of interest}

The authors declare no conflict of interest.

\section{References}

1. Parisi R, Symmons DPM, Griffiths CEM, Ashcroft DM. Identification and Management of Psoriasis and Associated Comorbidity (IMPACT) project team. Global epidemiology of psoriasis: a systematic review of incidence and prevalence. J Invest Dermatol 2013; 133: 377-85.

2. Ramessur R, Gill D. The effect of statins on severity of psoriasis: a systematic review. Indian J Dermatol Venereol Leprol 2017; 83: 154-61.

3. Huang PL. A comprehensive definition for metabolic syndrome. Dis Model Mech 2009; 2: 231-7.

4. Istvan ES. Structural mechanism for statin inhibition of 3-hydroxy-3-methylglutaryl coenzyme A reductase. Am Heart J 2002; 144: S27-32.

5. Bartlomiejczyk MA, Penson P, Banach M. Worldwide dyslipidemia guidelines. Curr Cardiovasc Risk Rep 2019; 13: 2.

6. Pirro M, Simental-Mendía L, Bianconi V, Watts G, Banach $M$, Sahebkar A. Effect of statin therapy on arterial wall inflammation based on 18F-FDG PET/CT: a systematic review and meta-analysis of interventional studies. J Clin Med 2019; 8: E118.

7. Egesi A, Sun G, Khachemoune A, Rashid RM. Statins in skin: research and rediscovery, from psoriasis to sclerosis. J Drugs Dermatol 2010; 9: 921-7.

8. Kim TG, Byamba D, Wu WH, Lee MG. Statins inhibit chemotactic interaction between CCL20 and CCR6 in vitro: possible relevance to psoriasis treatment. Exp Dermatol 2011; 20: 855-7.

9. Shirinsky IV, Shirinsky VS. Efficacy of simvastatin in plaque psoriasis: a pilot study. J Am Acad Dermatol 2007; 57: 529-31.

10. Colsman A, Sticherling M. Simvastatin in psoriasis: ambiguous effects. Acta Derm Venereol 2010; 90: 411.
11. Naseri M, Hadipour A, Sepaskhah M, Namazi MR. The remarkable beneficial effect of adding oral simvastatin to topical betamethasone for treatment of psoriasis: a double-blind, randomized, placebo-controlled study. Niger J Med 2010; 19: 58-61.

12. Vasiuk IA, Perlamutrov IN, Shkol'nik MN, Shkol'nik EL. Possibilities of atorvastatin in complex management of extensive psoriasis in patients with arterial hypertension. Kardiologiia 2010; 50: 37-46.

13. Brauchli YB, Jick SS, Meier CR. Statin use and risk of first-time psoriasis diagnosis. J Am Acad Dermatol 2011; 65: 77-83.

14. Faghihi T, Radfar M, Mehrabian Z, Ehsani AH, Rezaei Hemami M. Atorvastatin for the treatment of plaque-type psoriasis. Pharmacotherapy 2011; 31: 1045-50.

15. Ghazizadeh R, Tosa M, Ghazizadeh M. Clinical improvement in psoriasis with treatment of associated hyperlipidemia. Am J Med Sci 2011; 341: 394-8.

16. Aslam S, Khurshid K, Asad F, Rani Z, Pal SS. Efficacy and safety of simvastatin in chronic plaque psoriasis. J Pakistan Assoc Dermatol 2013; 23: 310-4.

17. Jacobi TC, Highet A. A clinical dilemma while treating hypercholesterolaemia in psoriasis. Br J Dermatol 2003; 149: 1305-6.

18. Thompson PD, Clarkson P, Karas RH. Statin-associated myopathy. JAMA 2003; 289: 1681.

19. Yamamoto M, Ikeda M, Kodama H, Sano S. Transition of psoriasiform drug eruption to psoriasis de novo evidenced by histopathology. J Dermatol 2008; 35: 732-6.

20. Cozzani E, Scaparro M, Parodi A. A case of psoriasis worsened by atorvastatin. J Dermatol Case Rep 2010; 3: 60-1.

21. Gressier L, Pruvost-Balland C, Dubertret L, Viguier M. Syndrome d'hypersensibilité médicamenteuse induit par l'atorvastatine. Ann Dermatol Venereol 2009; 136: 50-3.

22. Montanaro S, Lhiaubet-Vallet V, lesce MI, Previtera L, Miranda MA. A mechanistic study on the phototoxicity of atorvastatin: singlet oxygen generation by a phenanthrene-like photoproduct. Chem Res Toxicol 2009; 22: 173-8.

23. Moher D, Liberati A, Tetzlaff J, Altman DG; PRISMA Group. Preferred reporting items for systematic reviews and meta-analyses: the PRISMA statement. BMJ 2009; 339: b2535.

24. Glanville JM, Lefebvre C, Miles JNV, Camosso-Stefinovic J. How to identify randomized controlled trials in Medline: ten years on. J Med Libr Assoc 2006; 94: 130-6.

25. Higgins J, Altman D, Sterne J. Assessing risk of bias in included studies. In: Cochrane Handbook for Systematic Reviews of Interventions. Higgins J, Green S (eds.). John Wiley \& Sons, Ltd, London 2008; 187-241.

26. Chua SHH, Tioleco GMS, Dayrit CAF, Mojica WP, Dofitas BL, Frez LF. Atorvastatin as adjunctive therapy for chronic plaque type psoriasis versus betamethasone valerate alone: a randomized, double-blind, placebo-controlled trial. Indian J Dermatol Venereol Leprol 2017; 83: 441-7.

27. Trong HN, Tat TN, Anh TTN, et al. Efficacy of adding oral simvastatin to topical therapy for treatment of psoriasis: the vietnamese experience. Open Access Maced J Med Sci 2019; 7: 237-42.

28. Rysz-Górzynska M, Gluba-Brzózka A, et al. Efficacy of statin therapy in pulmonary arterial hypertension: a systematic review and meta-analysis. Sci Rep 2016; 6: 30060.

29. Banach M, Nikfar S, Rahimi R, et al. The effects of statins on blood pressure in normotensive or hypertensive sub- 
jects - a meta-analysis of randomized controlled trials. Lipid and Blood Pressure MetaAnalysis Collaboration Group. Int J Cardiol 2013; 168: 2816-24.

30. Barylski M, Nikfar S, Mikhailidis DP, et al. Statins decrease all-cause mortality only in CKD patients not requiring dialysis therapy: a meta-analysis of 11 randomized controlled trials involving 21,295 participants. Lipid and Blood Pressure Meta Analysis Collaboration Group. Pharmacol Res 2013; 72: 35-44.

31. Banach M, Dinca M, Ursoniu S, et al. A PRISMA-compliant systematic review and meta-analysis of randomized controlled trials investigating the effects of statin therapy on plasma lipid concentrations in HIV-infected patients. Lipid Blood Pressure Meta-analysis Collaboration Group. Pharmacol Res 2016; 111: 343-56.

32. Lesuis N, Befrits R, Nyberg F, van Vollenhoven RF. Gender and the treatment of immune-mediated chronic inflammatory diseases: rheumatoid arthritis, inflammatory bowel disease and psoriasis: an observational study. BMC Med 2012; 10: 82.

33. Luvai A, Mbagaya W, Hall AS, Barth JH. Rosuvastatin: a review of the pharmacology and clinical effectiveness in cardiovascular disease. Clin Med Insights Cardiol 2012; 6: 17-33.

34. Kim YS, Ahn Y, Hong MH, et al. Rosuvastatin suppresses the inflammatory responses through inhibition of c-Jun $\mathrm{N}$-terminal kinase and nuclear factor-kappaB in endothelial cells. J Cardiovasc Pharmacol 2007; 49: 376-83.

35. Rollefstad S, Ikdahl E, Hisdal J, et al. Rosuvastatin-induced carotid plaque regression in patients with inflammatory joint diseases: the rosuvastatin in rheumatoid arthritis, ankylosing spondylitis and other inflammatory joint diseases study. Arthritis Rheumatol 2015; 67: 1718-28.

36. Ikdahl E, Rollefstad S, Hisdal J, et al. Sustained improvement of arterial stiffness and blood pressure after longterm rosuvastatin treatment in patients with inflammatory joint diseases: results from the rora-as study. PLoS One 2016; 11: e0153440.

37. Ikdahl E, Hisdal J, Rollefstad S, et al. Rosuvastatin improves endothelial function in patients with inflammatory joint diseases, longitudinal associations with atherosclerosis and arteriosclerosis: results from the RORA-AS statin intervention study. Arthritis Res Ther 2015; 17: 279.

38. Banach M, Rizzo M, Toth PP, et al. Statin intolerance an attempt at a unified definition. Position paper from an International Lipid Expert Panel. Arch Med Sci 2015; 11: 1-23. 